\title{
Special modulator for high frequency, low-voltage plasma immersion ion implantation
}

\author{
Xiubo Tian, Xiaofeng Wang, ${ }^{\text {a) }}$ Baoyin Tang, and Paul K. Chu ${ }^{\text {b) }}$ \\ Department of Physics \& Materials Science, City University of Hong Kong, Kowloon, Hong Kong \\ Ping K. Ko \\ Hong Kong University of Science \& Technology, Clear Water Bay, Kowloon, Hong Kong \\ Yiu-Chung Cheng \\ Hong Kong University, Hong Kong
}

(Received 30 September 1998; accepted for publication 25 November 1998)

\begin{abstract}
Plasma immersion ion implantation is a burgeoning surface modification technique and not limited by the line-of-sight restriction plaguing conventional beam-line ion implantation. It is therefore an excellent technique to treat interior surfaces as well as components of a complex shape. To enhance the implant uniformity and increase the thickness of the modified layer, we are using a high frequency, low-voltage process to achieve high temperature and dose rate to increase the thickness of the modified layer. The low voltage conditions also lead to a thinner sheath more favorable to conformal implantation. In this article, we will describe our special modulator consisting of a single ended forward converter with a step-up transformer. The modulator is designed to operate from 5 to $35 \mathrm{kHz}$ and the output voltage is adjustable to an upper ceiling of $5000 \mathrm{~V}$ that is deliberately chosen to be our voltage limit for the present experiments. We will also present experimental data on SS304 stainless steel materials elucidating the advantages of our modulator and high frequency, low-voltage experimental protocols. (C) 1999 American Institute of Physics.
\end{abstract}

[S0034-6748(99)00803-5]

\section{INTRODUCTION}

Plasma immersion ion implantation (PIII) is a fledgling technique to modify the surface of materials and industrial components. ${ }^{1,2}$ It has a number of advantages over conventional ion beam ion implantation (IBII) such as high throughput and no line-of-sight restriction. The surface properties of many low-alloyed and microalloyed steels, stainless steel, tool steel, etc. have been successfully improved using PIII. ${ }^{3}$

One of the biggest advantages of PIII over IBII is the ability to implant objects possessing an irregular shape without beam rastering or target manipulation. However, the dose uniformity may be less than desirable especially when treating interior surfaces. ${ }^{4-6}$ Theoretically, conformal implantation can be achieved when the ion sheath is completely conformal around the target, but in practice, it is seldom the case due to the irregular shape of most real objects. Besides, the corners and edges pose a special challenge since the local sheath is especially nonuniform. ${ }^{7}$ It has been shown that the ion impact angle near a corner is oblique and the ion flux, which is enhanced above its planar value, peaks close to but not at the corner. ${ }^{8}$ Consequently, dose nonuniformity and sputtering that affects the retained dose are quite severe, and samples with sharp edges will exhibit considerable lateral dose variation. For samples with a wedge shape, the lateral

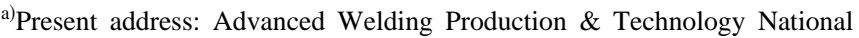
Key Laboratory, Harbin Institute of Technology, Harbin 150001, China.

b) Author to whom correspondence should be addressed; electronic mail: paul.chu@cityu.edu.hk
}

variation in the implanted argon concentration can be as high as a factor of 6 depending on the process parameters.9,10 Recent theoretical and experimental data ${ }^{11}$ have demonstrated that the thinner sheath achievable at a lower implantation voltage improves the lateral uniformity, but the thickness of the treated layer is compromised.

The implantation depth by PIII is usually smaller than that by IBII using beam-line ion implantation. Hence, it is relatively difficult to achieve a modified layer that is thick enough for real engineering applications. The reason is that the implantation voltage in PIII is impractical above $100 \mathrm{kV}$ due to expensive instrumentation and arcing. ${ }^{12}$ As an alternative, PIII can be carried out at an elevated temperature to increase the diffusion depth of the implanted species. Previous work has demonstrated that elevated temperature PIII (ET-PIII) works well for ferrous materials. The enhanced nitrogen diffusion increases the thickness of the modified materials and results in surface hardness and wear resistance improvement superior to those achieved by conventional IBII. ${ }^{13-15}$

Interestingly, recent reports ${ }^{16}$ have shown that the implantation voltage in ET-PIII may not be very crucial because different implantation voltage does not lead to a big difference in the surface hardness or wear resistance of the treated materials. Therefore, there are technical reasons favoring the use of a low implantation voltage, although highenergy bombardment does possess certain advantages, for instance, removing oxide layers which can prevent nitrogen 


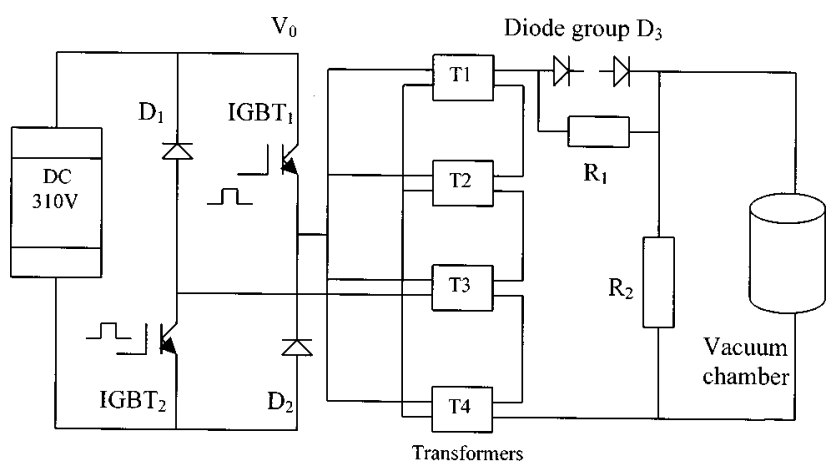

FIG. 1. Schematic of the high frequency, low-voltage modulator.

uptake or implantation through a surface layer. In order for low energy PIII to work, the implantation current must also be high. The high ion flux elevates the sample temperature and promotes fast diffusion of the implanted species to attain a thicker modified layer. ${ }^{17,18}$ Hence, it can be envisioned that a high frequency, low-voltage plasma immersion ion implantation process will be suitable for the implantation of interior surfaces or samples of an irregular shape. The high frequency raises the dose rate and consequently the sample temperature. Coupled with a low implantation voltage that reduces the sheath thickness, the lateral implant uniformity in samples of a complex shape can be improved. It is apparent that high frequency and low-energy are interdependent, and both parameters must be optimized to yield satisfactory results. In this work, we concentrate on high frequency pulsing at an implantation voltage less than $5 \mathrm{kV}$. Our newly developed power supply and its characteristics are also presented in this article.

\section{HIGH VOLTAGE PULSING}

There are two primary methods to generate high-voltage pulses. The first means is to employ an on-off switch to control the voltage. The second one is to use a switch in conjunction with a pulse-forming network (PFN) to generate the pulses. Both methods can be combined with a step-up transformer to attain the final required voltage. Generally speaking, switching pulse generators are more suitable and common in PIII. ${ }^{19,20}$ A survey on the high-voltage pulsing technology, including different pulse generator principles and requirements, can be found elsewhere. ${ }^{21}$ For lower voltage and peak power applications, solid state modulators are usually better. The switching device can be made of components from any high power device family. A comparison of their operation characteristics indicates that the IGBT is more desirable for the low-voltage, high frequency PIII process.

\section{PULSE GENERATOR DESIGN}

\section{A. Main power circuit}

To satisfy the requirements of high frequency, lowenergy PIII, we use a single-ended forward converter as our modulator due to its lower power. A forward converter requires the polarity of the primary coil of the transformer to be identical to that of the secondary one, and so the energy of

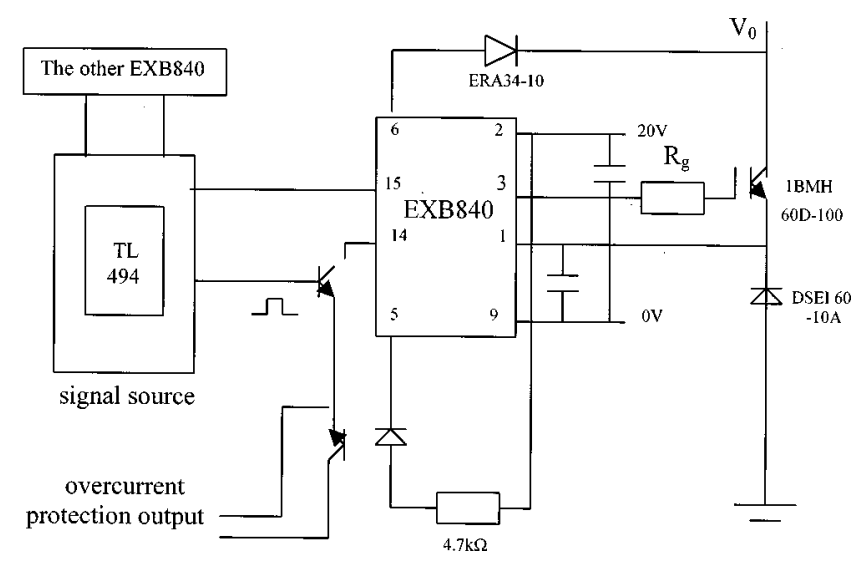

FIG. 2. Drive circuit of IGBTs with IC EXB840.

the load is obtained during the on state of the switching device. For the flyback converter, on the contrary, the power supply provides the energy with the load during the off state owing to the difference in the polarity of these two coils. The maximum duty cycle of $50 \%$ for a single-ended forward converter is not a shortcoming, as high frequency implantation is usually coupled with small pulse widths. It is more desirable to use a short implantation pulse to allow ample time for plasma recuperation in between pulses. However, an auxiliary transformer core reset supply is required to attain the optimal pulse transformer performance because of demagnetizing during the off cycle of the switching device. Thus, we utilize a variation of the single-ended forward converter by using two switching devices and two diodes, as shown in Fig. 1. The advantage of this arrangement stems from the fact that the IGBTs are subject to only half the maximum voltage in comparison with the circuit using only a switching device, i.e., only $V_{0}$ instead of two $V_{0} s$. Moreover, the power transformer $T$ (including T1, T2, T3, T4) requires no reset winding and is thus simpler. The circuit operates in the following mode. When the drive signals are imposed on the two IGBTs (1MBH60D-100) $)^{22}$ at the same time, they are turned on simultaneously. The primary current flows from V0 through IGBT1, the primary winding of $T$, and IGBT2. In this period, a back voltage is induced in the primary winding, and the forward converter transfers the signal to the secondary side. The diode group D3 conducts, and the current is delivered to the sample to carry out ion implantation. When the drive signal is negative $(-5 \mathrm{~V})$, both switching IGBTs are turned off. Since an abrupt interruption of the primary current of $T$ produces a high induced voltage, a path is provided for the decay of this current and demagnetization of $T$ through diodes D1 and D2. To demagnetize completely,

TABLE I. Properties of EXB840 drive device for IGBT.

\begin{tabular}{lc}
\hline \hline \multicolumn{1}{c}{ Specification } & Rated value \\
\hline Power supply voltage $(\mathrm{V})$ & 25 \\
Input current of the inner optocoupler $(\mathrm{mA})$ & 10 \\
Separation voltage $(\mathrm{kV})$ & 2.5 \\
Working surface temperature $\left({ }^{\circ} \mathrm{C}\right)$ & $-10-+85$ \\
Storage temperature $\left({ }^{\circ} \mathrm{C}\right)$ & $-25-+125$ \\
\hline \hline
\end{tabular}




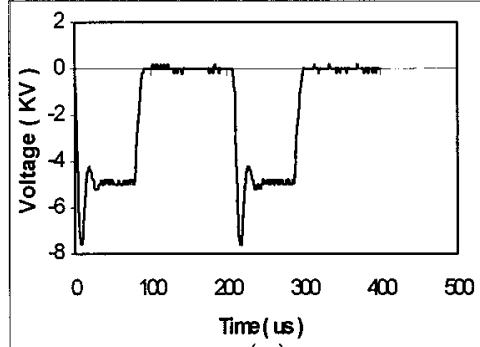

(a)
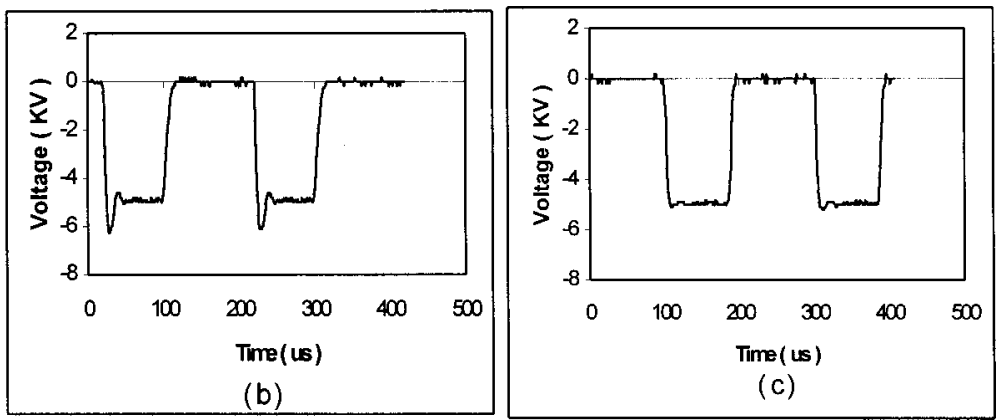

FIG. 3. Voltage wave forms for different plasma density: (a) without plasma, (b) low plasma density, and (c) high plasma density.

$T_{\text {on }}$ must be smaller than $T_{\text {off }}$, otherwise the IGBTs will be damaged owing to the failure of the transformer. ${ }^{23}$

A rectified ac line voltage with sequential filtration is used to supply the power to the circuit. Voltage step up is thus necessary to attain the required high voltage. We utilize four transformers with a ratio of 1:4 each. They work in two modes and in a synchronous manner. The first mode is that the primary coils operate in parallel and the secondary windings are connected in series. Thus, a $310 \mathrm{~V}$ dc input can produce a $4960 \mathrm{~V}$ pulsed ac output to the plasma load. In the second mode, the secondary coils work in parallel to increase the capacity. However, the transformation ratio is limited to 1:4 to reduce the distributed capacitance because it is proportional to the square of the ratio. The design and manufacturing of the transformers is very crucial, as they determine the output characteristics of the modulator and safe service. Although the maximum output voltage of each transformer is only about $1 \mathrm{kV}$, the required voltage should be more than 5 $\mathrm{kV}$. In our engineering design, the voltage is $10 \mathrm{kV}$. In addition, the high frequency working condition needs special consideration on the diameter of the coil wire due to the skin effect. The number of turns on the transformer windings should be reduced so that the modulator can achieve abrupt voltage variation to ensure monoenergetic implantation. The main circuit is designed to operate from 5 to $35 \mathrm{kHz}$. The output voltage is adjustable to an upper ceiling of $5000 \mathrm{~V}$ that is deliberately chosen to be our voltage limit for the present experiments

\section{B. Drive circuit}

To accomplish satisfactory switching behavior in the IGBTs, particular attention must be paid to the drive circuit. A special integrated circuit (IC) is used to ensure that the generator works safely and reliably. The schematic of the drive circuit is displayed in Fig. 2. Its core is the drive module EXB $840,{ }^{22}$ which is a high-speed drive device and suitable for $40 \mathrm{kHz}$ working conditions. The inner circuit uses an optocoupler to separate the input signal from output signal so that the EXB840 can be directly used to drive the highvoltage devices. Its optimal working conditions are shown in Table I. Our experiments show that 1BMH60D-100 can be damaged if a high drive voltage is applied and a lower drive voltage can give rise to a bigger on-state voltage drop. The value of $R_{g}$ also has a big influence on the operating characteristics of the IGBT. A proper $R_{g}$ can effectively reduce the sharp voltage surge of the collectors of the IGBTs. For the IGBTs of $1 \mathrm{BMH} 60 \mathrm{D}-100$, an $R_{g}$ of $25 \Omega$ is selected to achieve a more abrupt voltage change in this modulator. The EXB840 is composed of an amplification circuit, an overcurrent protection circuit and a $5 \mathrm{~V}$ reference voltage circuit. The primary signal source is a commercial TL494 device producing two $10 \mathrm{~V}$ signals with a duty cycle below $50 \%$ to meet the requirement of transformer demagnetization. They control the output of the module EXB840. Pin Nos. 3 and 1 of EXB840 give a square wave pulse of -5 to $+18 \mathrm{~V}$ to control the IGBTs. The $+18 \mathrm{~V}$ signal is used to switch on the IGBT and the $-5 \mathrm{~V}$ signal can effectively prevent the misconduct during the off time. The EXB840 provides overcurrent protection for the IGBTs. When the IGBT sees all the current, $V_{\text {ce }}$ of the IGBT will increase immediately to cut off the diode ERA34-10 and electrically float pin No. 6. The potential on pin No. 3 finally decreases thereby cutting off the IGBT gradually. All the steps are automatically controlled by the inner circuit of the EXB840. Special attention must be paid to ascertain that the drive circuit is composed of three independent power supplies, one for the signal source TL494 and two for the EXB840 modules.

\section{RESULTS AND DISCUSSION}

To evaluate the performance of our modulator and efficacy of the high frequency, low-voltage PIII process, experi-

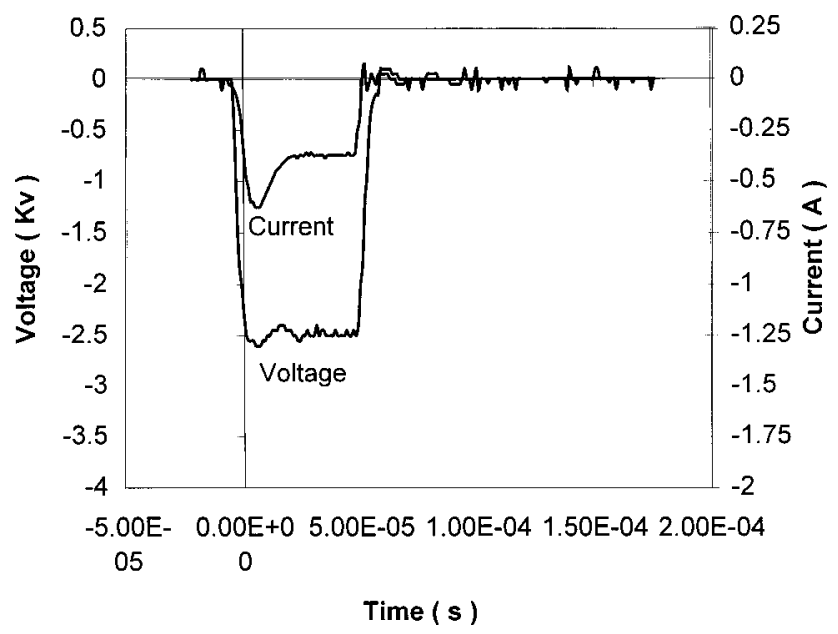

FIG. 4. Output voltage and current wave forms of the generator. The working conditions are: $2.5 \mathrm{kV}$ implantation voltage, $50 \mu$ s duration, and 8.5 $\mathrm{KHz}$ 
TABLE II. Experimental conditions and results.

\begin{tabular}{cccccc}
\hline \hline Sample & $\begin{array}{c}\text { Implant } \\
\text { voltage } \\
(\mathrm{kV})\end{array}$ & $\begin{array}{c}\text { Pulse } \\
\text { frequency } \\
(\mathrm{kHz})\end{array}$ & $\begin{array}{c}\text { Pulse } \\
\text { duration } \\
(\mu \mathrm{s})\end{array}$ & $\begin{array}{c}\text { Implant } \\
\text { time } \\
(\mathrm{min})\end{array}$ & $\begin{array}{c}\text { Microhardness } \\
\text { HV (50 g load })\end{array}$ \\
\hline 1 & unimplanted & $\ldots$ & $\ldots$ & $\ldots$ & 250 \\
2 & 1.5 & 8.5 & 30 & 200 & 302 \\
3 & 2.0 & 8.5 & 30 & 200 & 320 \\
4 & 3.5 & 5.0 & 50 & 200 & 380 \\
5 & 5.2 & 1.0 & 35 & 200 & 270 \\
\hline \hline
\end{tabular}

ments were performed on SS304 stainless steel samples. The newly designed generator was first connected to the sample stage of our PIII equipment that has been described in detail elsewhere. ${ }^{24,25}$ During installation of the hardware, the electrical distribution parameters were reduced as much as possible, because high frequency and high-voltage operation conditions might amplify these parameters and damage the converter. The distributed inductance and capacitance of the transformer affect the output voltage wave form shown in Fig. 3. It was observed that oscillation of the voltage wave form without a plasma load was very severe leading to a voltage peak that was higher by a factor of 1.5 . When the plasma was ignited using nitrogen glow discharge, the oscillation peak value gradually decreased. Eventually, the oscillation was nearly damped out and the voltage rise time increased significantly when the plasma density was higher. The resistor $R_{1}$ parallel to the diode group influences the fall time of the wave form, and more importantly, it can be used to obtain a positive voltage to attract electrons to heat the sample or change the sheath dynamics and plasma refilling. $R_{1}$ with $R_{2}$ also determine the discharge constant of the plasma vacuum capacitor and affect the output voltage wave form of the modulator. The value of the resistors should balance the output characteristics and the efficiency of the power supply. For example, a smaller resistor is preferred for implantation but harmful to the modulator. Figure 4 exhibits the voltage and current wave form at $2.5 \mathrm{kV}$ with a pulse duration of $50 \mu$ s under a practical plasma load. It can be

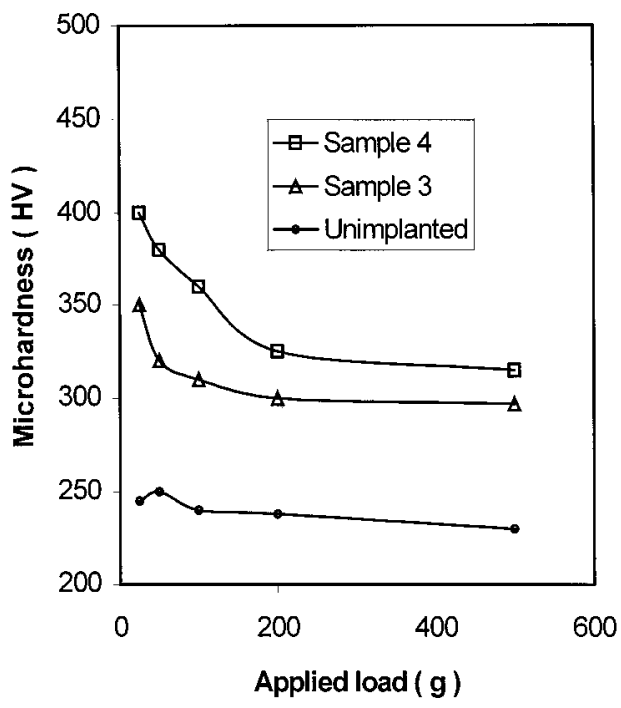

FIG. 5. Surface hardness improvement after high frequency, low-voltage plasma immersion ion implantation treatment. observed that the ion sheath stabilizes very promptly when the voltage is low. This leads to better dose uniformity.

SS304 stainless steel specimens were treated using our newly developed modulation and the high frequency, lowvoltage process. The experimental conditions and results are displayed in Table II. The hardness measurement of the treated and unimplanted samples was carried out on an HX1000 microhardness tester. The relationship of the microhardness with the applied load is depicted in Fig. 5. There is a discernible improvement in all the treated samples and the maximum improvement is observed to be more than $60 \%$ with a $25 \mathrm{~g}$ load. It is evident that the greater the applied load, the smaller the hardness value. In particular, the sample treated at $3.5 \mathrm{kV}$ demonstrates the most dramatic hardness improvement, and the microhardness with a test load of 500 $\mathrm{g}$ is higher by $30 \%$ than that of the unimplanted sample. This indicates that the modified zone using the high frequency, low-voltage process is much thicker than the implanted layer. In comparison, in spite of the high implantation voltage, the microhardness of sample 5 is lower. Its hardness is only slightly higher than that of the unimplanted sample and it can be attributed to the lower implantation dose rate and subsequently lower temperature. Therefore, it can be inferred that substantial diffusion has taken place during the high frequency and low-voltage PIII step due to the high ion flux (consequently high temperature, $>300^{\circ} \mathrm{C}$ ) and radiation induced diffusion. The results confirm the benefits of our process and that our modulator works as designed.

\section{ACKNOWLEDGMENTS}

This work was supported by City University of Hong Kong Strategic Grant No. 7000730 and Hong Kong Research Grants Council Earmarked Grant Nos. 9040332 and 9040344.

${ }^{1}$ J. R. Conrad, J. I. Radtke, R. A. Dodd, F. J. Worzala, and N. C. Tran, J. Appl. Phys. 62, 4591 (1987).

${ }^{2}$ J. V. Mantese, I. G. Brown, N. W. Cheung, and G. A. Collins, MRS Bull. 21, 52 (1996).

${ }^{3}$ W. Ensinger, Surf. Coat. Technol. 100-101, 341 (1998).

${ }^{4}$ A. G. Liu, X. F. Wang, B. Y. Tang, and P. K. Chu, J. Appl. Phys. 84, 1859 (1998).

${ }^{5}$ A. G. Liu, X. F. Wang, Q. C. Chen, B. Y. Tang, and P. K. Chu, Nucl. Instrum. Methods Phys. Res. B 43, 306 (1998).

${ }^{6}$ X. C. Zeng, T. K. Kwok, A. G. Liu, P. K. Chu, B. Y. Tang, and T. E. Sheridan, IEEE Trans. Plasma Sci. 26, 1 (1998).

${ }^{7}$ P. A. Watterson, J. Phys. D 22, 1300 (1989).

${ }^{8}$ T. E. Sheridan, J. Phys. D 29, 2725 (1996).

${ }^{9}$ W. Ensinger, T. Hochbauer, and B. Rauschenbach, Surf. Coat. Technol. 103-104, 218 (1998).

${ }^{10} \mathrm{~W}$. Ensinger, T. Hochbauer, and B. Rauschenbach, Surf. Coat. Technol. 94-95, 352 (1997).

${ }^{11}$ M. M. Shamim, D. E. Muller, K. Sridharan, R. P. Fetherston, N. Tran, and J. R. Conrad, J. Appl. Phys. 77, 1015 (1995).

${ }^{12}$ D. J. Rej, R. J. Faehl, and J. N. Matossian, Surf. Coat. Technol. 96, 45 (1997).

${ }^{13}$ S. M. Johns, T. Bell, M. Smamandi, and G. A. Collins, Surf. Coat. Technol. 85, 7 (1996).

${ }^{14}$ C. Blawert, A. Weisheit, B. L. Mordike, and F. M. Knoop, Surf. Coat. Technol. 85, 15 (1996).

${ }^{15}$ C. Blawert, B. L. Mordike, U. Huchel, S. S. Tramke, G. A. Collins, K. T. Short, and J. Tendys, Surf. Coat. Technol. 98, 1181 (1998).

${ }^{16}$ G. A. Collins, R. Hutchings, K. T. Short, and J. Tendys, Surf. Coat. Technol. 103-104, 212 (1998). 
${ }^{17}$ D. L. Williamson, J. A. Davis, and P. J. Wilbur, Surf. Coat. Technol. 103-104, 178 (1998).

${ }^{18}$ R. Wei, Surf. Coat. Technol. 83, 218 (1996).

${ }^{19}$ J. Brutscher, Rev. Sci. Instrum. 67, 2621 (1996).

${ }^{20}$ D. Deb, J. Siambis, and R. Symons, J. Vac. Sci. Technol. B 12, 828 (1994).

${ }^{21}$ W. A. Reass, J. Vac. Sci. Technol. B 12, 854 (1994).
${ }^{22}$ Commercial product of Fuji Electric Co., Ltd., Japan.

${ }^{23}$ O. Kilgenstein, Switch-Mode Power Supplies in Practice (Wiley, New York, 1989).

${ }^{24}$ P. K. Chu, B. Y. Tang, Y. C. Cheng, and P. K. Ko, Rev. Sci. Instrum. 68, 1866 (1997).

${ }^{25}$ P. K. Chu, S. Qin, C. Chan, N. W. Cheung, and L. A. Larson, Mater. Sci. Eng., R. R17, 207 (1996). 